\title{
TRATADOS INTERNACIONAIS NO ORDENAMENTO JURÍDICO BRASILEIRO: CONVENÇÃO AMERICANA SOBRE DIREITOS HUMANOS E LIBERDADE DE EXPRESSÃO
}

\section{ARTIGO ORIGINAL}

AKABASSI, Evelyne ${ }^{1}$

AKABASSI, Evelyne. Tratados internacionais no ordenamento jurídico brasileiro: convenção americana sobre direitos humanos e liberdade de expressão. Revista Científica Multidisciplinar Núcleo do Conhecimento. Ano 06, Ed. 07, Vol. 05, pp. 116-130. Julho de 2021. ISSN: 2448-0959, Link de acesso: https://www.nucleodoconhecimento.com.br/lei/ordenamento-juridico, 10.32749/nucleodoconhecimento.com.br/lei/ordenamento-juridico

\section{RESUMO}

A liberdade de expressão consta do ordenamento jurídico brasileiro como uma das principais garantias fundamentais da Constituição Federal de 1988, e é reforçada na Convenção Americana sobre Direitos Humanos de 1969 ratificada pelo Brasil. O presente artigo tem como questão norteadora: Há cerceamento do direito fundamental à liberdade de expressão previsto na Carta Magna de 1988 e na Convenção Americana de Direitos Humanos de 1969 em caso de tipificação de desacato de acordo com o Código Penal e o Código Penal Militar? Tem a finalidade de investigar se é possível falar em cerceamento do direito à liberdade de expressão em caso de crime de desacato. Neste contexto, foram realizadas pesquisas e análises jurisprudenciais sobre o tema, bem como revisão bibliográfica pautada em obras de juristas consagrados, artigos científicos em periódicos e sites especializados. Ademais, analisou-se como a decisão do Habeas Corpus 141.949,

\footnotetext{
${ }^{1}$ Especialista em Direito Aplicado pela Escola Superior da Magistratura do Estado do Espírito Santo (ESMAGES), especialista em Direito Público pela Pontifícia Universidade Católica de Minas Gerais (PUC Minas) e bacharel em Direito pela Universidade Federal Fluminense (UFF).
}

RC: 91174

Disponível em: https://www.nucleodoconhecimento.com.br/lei/ordenamento-juridico 
do Distrito Federal, julgado pela Segunda Turma do Supremo Tribunal Federal em 2018 cristalizou um relevante precedente ao entender, no caso concreto, que o crime de desacato não afronta o disposto na Constituição Federal ou o previsto na Convenção Americana de Direitos Humanos. A partir desta pesquisa foi possível demonstrar a existência de compatibilidade entre o direito à liberdade de expressão, previsto em ambos os regulamentos normativos, e o crime de desacato disposto na legislação penal brasileira, o que conduz a uma maior segurança jurídica em caso de futuras demandas judiciais sobre a matéria.

Palavras-chave: Direito constitucional, Direitos humanos, Controle de convencionalidade, Tratados internacionais, Liberdade de expressão.

\section{INTRODUÇÃO}

A Convenção Americana sobre Direitos Humanos de 1969, também conhecida como Pacto de San José da Costa Rica, é um documento em que o Brasil é signatário e que, em seu artigo 13, trata da garantia de liberdade de expressão aos indivíduos. A partir da análise do controle de convencionalidade adotado no Brasil para a incorporação do referido tratado internacional de direitos humanos ao ordenamento jurídico pátrio, da previsão do direito à liberdade de expressão e de pensamento na Constituição Federal de 1988 (art. 5, incisos IV e IX e art. 220, caput e $\S 2^{\circ}$ ), e da tipificação do desacato no ordenamento jurídico interno (art. 331 do Código Penal e art. 299 do Código Penal Militar), observa-se a possibilidade de conflito de normas no que tange à garantia desta liberdade:

Art. 5ำ Todos são iguais perante a lei, sem distinção de qualquer natureza, garantindo-se aos brasileiros e aos estrangeiros residentes no País a inviolabilidade do direito à vida, à liberdade, à igualdade, à segurança e à propriedade, nos termos seguintes: [...] IV - é livre a manifestação do pensamento, sendo vedado o anonimato; [...] IX - é livre a expressão da atividade intelectual, artística, científica e de comunicação, independentemente de censura ou licença; (BRASIL. Constituição da Republica Federativa do Brasil, 1988.).

Art. 220. A manifestação do pensamento, a criação, a expressão e a informação, sob qualquer forma, processo ou veículo não sofrerão qualquer

RC: 91174

Disponível em: https://www.nucleodoconhecimento.com.br/lei/ordenamento-juridico 
restrição, observado o disposto nesta Constituição. [...] § $2^{\circ}$ É vedada toda e qualquer censura de natureza política, ideológica e artística. (BRASIL. Constituição da Republica Federativa do Brasil, 1988.)

Art. 331 - Desacatar funcionário público no exercício da função ou em razão dela:

Pena - detenção, de seis meses a dois anos, ou multa. (BRASIL. Código Penal, 1940.)

Art. 299. Desacatar militar no exercício de função de natureza militar ou em razão dela:

Pena - detenção, de seis meses a dois anos, se o fato não constitui outro crime. (BRASIL, 1969.)

A partir da obra de Piovesan (2013), é possível inferir que o direito internacional adentra a contemporaneidade como uma espécie de árbitro para a elaboração de costumes e tratados internacionais capazes de guiar, de maneira mais correta, os preceitos básicos dos direitos humanos, tendo papel fundamental para a não perpetuação de regimes totalitaristas ou contrários à proteção da dignidade humana. Nessa mesma esteira, o direito constitucional se amolda como responsável pela inserção desses tratados internacionais no ordenamento jurídico pátrio, através do controle de convencionalidade, de modo a garantir que a ratificação feita pelo Brasil não seja inócua.

Depreende-se, com base no trabalho de Loureiro (2004), que os acordos internacionais, independentemente de serem ou não sobre direitos humanos, são elaborados por um conjunto de Estados Soberanos que optam por abrir mão de parte de sua soberania com o intuito estabelecer normas capazes de reger o entendimento sobre assuntos de caráter universal, isto é, cuja importância estendese à coletividade. Ademais, sabe-se que a recepção de diretrizes internacionais no ordenamento interno é uma solenidade de cunho complexo e proveniente de ato do Presidente da República - em suas atribuições como Chefe de Estado - sujeita, posteriormente, à aprovação pelo Congresso Nacional.

RC: 91174

Disponível em: https://www.nucleodoconhecimento.com.br/lei/ordenamento-juridico 
Neste ínterim, apresenta-se a seguinte questão norteadora deste artigo: Há cerceamento do direito fundamental à liberdade de expressão previsto na Carta Magna de 1988 e na Convenção Americana de Direitos Humanos de 1969 em caso de tipificação de desacato de acordo com o Código Penal e o Código Penal Militar?

O tema desacato - englobam-se, no presente trabalho, o desacato a funcionário público no exercício da função previsto no artigo 331 do Código Penal; bem como o desacato a militar no exercício da função do artigo 299 do Código Penal Militar - é fonte de debate, tendo sido analisado em diversas oportunidades tanto pelo Superior Tribunal de Justiça quanto pelo Supremo Tribunal Federal.

Apesar de não haver pacificação jurisprudencial acerca do tema até o momento, o Habeas Corpus 141.949 do Distrito Federal julgado pela Segunda Turma Supremo Tribunal Federal em 2018 obteve veredito fundamental para a criação de um precedente jurídico positivo no que tange ao reconhecimento e efetiva aplicabilidade da Convenção Americana sobre Direitos Humanos ao ordenamento jurídico brasileiro, visto que sacramentou que a tipificação do desacato no Código Penal e no Código Penal Militar não interfere do direito à liberdade de expressão previstos na Constituição Federal de 1988 e na Convenção Interamericana sobre Direitos Humanos. Deste modo, a referida decisão teve o condão de influenciar processos já em curso e fazer-se constar como jurisprudência basilar para casos futuros que versem sobre o assunto.

\section{DESENVOLVIMENTO}

O panorama de proteção aos direitos humanos, segundo Galindo (2002) começa a despontar na França a partir da Declaração dos Direitos do Homem e do Cidadão, de 1789. Todavia, no Brasil, esse ideal de proteção, já presente nas diretrizes internacionais, só começou a ser empregado efetivamente com a promulgação da Constituição Federal de 1988, durante a redemocratização do Estado Brasileiro. $\mathrm{Na}$ contemporaneidade, destacam-se importantes "documentos-fonte" do Direito Internacional, como é o caso da Carta das Nações Unidas de 1945 e da Declaração

RC: 91174

Disponível em: https://www.nucleodoconhecimento.com.br/lei/ordenamento-juridico 
Universal dos Direitos Humanos de 1948. O mundo, então, passou a conhecer uma nova forma de os Estados Soberanos se relacionarem no âmbito internacional, devendo seguir preceitos como a cooperação internacional, proteção internacional dos direitos humanos, prática da tolerância e manutenção da paz.

Para Rezek (2011), após o período ditatorial, viu-se a necessidade de ampliar o rol de direitos e garantias fundamentais a serem protegidos pelo Estado - que passou a ser um Estado Democrático de Direito. Esse é um dos principais alicerces desse tipo de organização do Estado, visto que após um período de privação exacerbada de direitos por parte do próprio governo, reacende-se a urgência na adoção de medidas capazes de resguardar os cidadãos para que as atrocidades vividas no lapso autocrático não se repitam. Sendo assim, sob a ótica de Piovesan (2013), a Constituição Republicana de 1988 se consolidou como a Lei Fundamental do Estado Brasileiro, contendo nos direitos humanos e nas garantias fundamentais uma espécie de regulamento jurídico preliminar no que diz respeito ao direito dos indivíduos, de sorte que passou a ser possível vislumbrar a condição bidimensional dos direitos mencionados no sistema normativo pátrio. Tal bidimensionalidade se caracteriza pelo fato de a dignidade humana passar a ser devidamente protegida tanto na esfera nacional, quanto no âmbito internacional - através dos tratados e convenções ratificados pelo Brasil -, o que acaba por demonstrar a complementariedade e a dialogação entre ambas as fontes normativas.

Entretanto, fazer com que tais diplomas normativos internacionais sejam efetivamente aplicados pelo ordenamento jurídico interno ainda é um desafio apesar do controle de convencionalidade exercido pela alta cúpula do Poder Judiciário do país.

\section{O CONTROLE DE CONVENCIONALIDADE BRASILEIRO NA ERA CONTEMPORÂNEA}

A partir do disposto no art. $5^{\circ}$ da Constituição Federal de 1988, evidencia-se que o Estado brasileiro compactua com a prevalência dos direitos humanos e aceita a

RC: 91174

Disponível em: https://www.nucleodoconhecimento.com.br/lei/ordenamento-juridico 
existência de limites e condicionamentos à noção de soberania estatal. Conforme exposto por Rezek (2011), uma vez ratificados, esses documentos possuem o condão de vincular todo o Poder Público à medida em que criam obrigações jurídicas para os Estados-membros como principal fonte normativa do Direito Internacional. Tais obrigações não vigoram apenas entre Estados-membros, mas também no plano interno dessas nações, criando-se um bloco de constitucionalidade.

Ainda segundo Rezek (2011), o Brasil emprega a lógica do bloco de constitucionalidade ao entender o ordenamento interno como uma pirâmide: no topo dela encontra-se a Constituição Federal juntamente às Emendas Constitucionais e aos tratados internacionais de direitos humanos que atenderam aos critérios do parágrafo $3^{\circ}$ do art. 5․ Os demais tratados, mesmo que de direitos humanos, adentram o ordenamento jurídico com status de norma supralegal, não podendo ser equiparados à Constituição. Sendo assim, quando se diz respeito, especificamente, aos tratados internacionais de direitos humanos, o ordenamento jurídico brasileiro estabelece, entre os tratados e as normas internas, diretrizes que são visíveis nos parágrafos $2^{\circ}$ e $3^{\circ}$ do art. $5^{\circ}$ da Constituição Federal de 1988:

Art. $5^{\circ}$ Todos são iguais perante a lei, sem distinção de qualquer natureza, garantindo-se aos brasileiros e aos estrangeiros residentes no País a inviolabilidade do direito à vida, à liberdade, à igualdade, à segurança e à propriedade, nos termos seguintes: [...]

$\S 2^{\circ}$ Os direitos e garantias expressos nesta Constituição não excluem outros decorrentes do regime e dos princípios por ela adotados, ou dos tratados internacionais em que a República Federativa do Brasil seja parte.

$\S 3^{\circ}$ Os tratados e convenções internacionais sobre direitos humanos que forem aprovados, em cada Casa do Congresso Nacional, em dois turnos, por três quintos dos votos dos respectivos membros, serão equivalentes às emendas constitucionais. (Incluído pela Emenda Constitucional $\mathrm{n}^{\circ} \mathbf{4 5}$, de 2004) (BRASIL, 1988).

Os supramencionados parágrafos da Constituição Federal de 1988, são a fundamentação para a aceitação dos tratados internacionais de direitos humanos no sistema jurídico brasileiro. De acordo com o entendimento de Loureiro (2004), ao 
admitir a incorporação do direito internacional no direito interno, a Carta Maior atribui aos direitos internacionais o "status" de norma constitucional. Ou seja, os direitos constantes nos tratados internacionais de direitos humanos ratificados pelo Brasil farão, automaticamente, parte do rol de direitos reconhecidos pela Constituição vigente.

Acerca da recepção dos tratados e convenções internacionais que versam sobre diretos humanos no arcabouço jurídico pátrio, Mazuolli (2009) sustenta que é necessário uma análise pormenorizada do controle de convencionalidade para que tais regulamentações sejam plenamente eficazes dentro do sistema normativo brasileiro. Insta frisar que a adoção do controle de convencionalidade, e consequente recepção de normas externas, em nada impede que o Estado elabore diretrizes nacionais que ampliem os direitos e garantias fundamentais dos indivíduos, desde que o núcleo dos acordos internacionais de direitos humanos ratificados pelo Brasil seja devidamente resguardado.

A propósito, de acordo com o que fora elucidado por Rezek (2011), quando se trata de direitos humanos, é preciso levar em consideração que garantias e liberdades fundamentais devem ser preservadas ao máximo, de modo a evitar retrocessos. É inegável que alterações são permitidas, contudo, por serem classificadas como cláusulas pétreas, o conteúdo que versa sobre esses direitos jamais poderá ser suprimido da Carta Magna. E para que o bloco de constitucionalidade seja capaz de vincular atos ou decisões - não só judiciais, mas também administrativas -, é preciso que o processo de incorporação das normas internacionais seja rigorosamente respeitado de forma que, ao versar sobre direitos humanos, prevaleçam os princípios da dignidade da pessoa humana e da isonomia. Somente desta maneira é possível criar um sistema jurídico seguro e harmônico, apto a proteger plenamente seus indivíduos.

RC: 91174

Disponível em: https://www.nucleodoconhecimento.com.br/lei/ordenamento-juridico 


\section{O CASO CONCRETO DO HABEAS CORPUS 141.949 DO DISTRITO FEDERAL JULGADO PELO STF}

O Habeas Corpus (HC) 141.949 do Distrito Federal, julgado em 13 de março de 2018 pela Segunda Turma do Supremo Tribunal Federal (STF), teve como relator o Ministro Gilmar Mendes. O caso em questão tinha como paciente o Sr. Admys Francisco de Souza Gomes e como impetrante o Sr. Rafael de Deus Garcia, verificando-se ainda o Superior Tribunal Militar como parte coatora.

O referido Habeas Corpus trata do crime de desacato praticado pelo civil, Sr. Rafael, contra o $2^{\circ}$ sargento, que se encontrava no exercício de sua função na $4^{a}$ Seção do Batalhão da Guarda Presidencial, localizada em Brasília. Na oportunidade, conforme narrado no julgado, o civil teria chamado o militar de "palhaço", atitude essa que teria ensejado a sua prisão com base no artigo 299 do Código Penal Militar.

Todavia, a questão debatida na Segunda Turma do STF trouxe à tona argumentações com o intuito de esclarecer se o desacato fere ou não a Constituição Federal Brasileira e a Convenção Americana de Direitos Humanos. Atualmente, a Carta Magna do Brasil assegura aos seus cidadãos o direito à liberdade de expressão e de pensamento, conforme disposto nos artigos. 5ㅜㅗ incisos IV e IX, e 220 - caput e $\S 2^{\circ}$. Já na Convenção Americana de Direitos Humanos, tais garantias se encontram em seu artigo 13.

A decisão da Segunda Turma do STF no HC 141.949, ainda que não tenha sido por unanimidade, denegou o Habeas Corpus impetrado, mantendo a condenação da Justiça Militar que pugnou pela existência do crime de desacato a militar. O Ministro Gilmar Mendes, que atuou como relator do caso, votou pela não concessão do Habeas Corpus, de modo a não reconhecer a nulidade da condenação do acusado. Mendes argumentou que a punição existente no sistema jurídico pátrio pelo crime de desacato tem o condão de resguardar tanto o exercício da função pública, quanto o próprio Estado Brasileiro. Na ocasião, o relator teve seu voto acompanhado pelos ministros Ricardo Lewandowski e Dias Toffoli. 
A contraposição, no entanto, ficou por parte do ministro Edson Fachin, que defendeu a concessão do Habeas Corpus e o reconhecimento da nulidade da condenação mediante a aplicação do Pacto de San José da Costa Rica, cujo conteúdo não seria compatível com a criminalização do desacato. Arguiu ainda que tratar a referida conduta como crime equivaleria a uma medida desproporcional, violando os direitos dos cidadãos no que diz respeito à liberdade de expressão e pensamento. Por fim, asseverou que o sistema jurídico brasileiro, em especial a Constituição, não corrobora com a tipificação do desacato. Ante sua perspectiva, o direito à liberdade de expressão é essencial para a manutenção do Estado Democrático de Direito, que se vê ameaçado pela tipificação do desacato.

Destarte, os argumentos de Fachin não foram suficientes para evitar a denegação do remédio constitucional. Toffoli e Lewandowski acompanharam o voto denegatório do relator Gilmar Mendes, que defendeu veementemente a validade da decisão do Superior Tribunal Militar, ao explanar que a atitude do impetrante obstaculiza o funcionamento e a eficiência do Estado Brasileiro que se vê representado nas pessoas de seus funcionários públicos, sejam eles civis ou militares. Suscitou que não se deve falar em incompatibilidade do dispositivo presente no Código Penal Militar e o disposto Carta Magna e no Pacto de San José, por endender que a norma penal não foi revogada com o advento dos referidos diplomas, mas sim recepcionada por eles. Neste sentido, explicitou que:

A liberdade de expressão prevista na Convenção Americana de Direitos Humanos não difere do tratamento conferido pela Constituição Federal ao mesmo tema, não possuindo esse específico direito, como todos os demais direitos fundamentais, caráter absoluto.

A Constituição Federal, ao tutelar a honra, a intimidade e a dignidade da pessoa humana, direitos conferidos a todos, sem distinção de qualquer natureza (art. 5o da CF), recepcionou a norma do desacato prevista na legislação penal.

O direito à liberdade de expressão deve harmonizar-se com os demais direitos envolvidos (honra, intimidade e dignidade), não eliminá-los. Incide o princípio da concordância prática, pelo qual o intérprete deve buscar a conciliação entre normas constitucionais. (BRASIL. Supremo Tribunal

RC: 91174

Disponível em: https://www.nucleodoconhecimento.com.br/lei/ordenamento-juridico 
Federal. Recurso de Habeas Corpus. Habeas Corpus no 141.949, 2018, p. 10.)

Ademais, arguiu que para que se possa garantir a Democracia e devida a proteção do Estado aos ataques de seus nacionais, não sendo pertinente deixar seus funcionários sem a garantia de que podem executar as diretrizes estatais sem sofrer represálias. Quanto ao argumento dos defensores da descriminalização que entendem que a tipificação do desacato dá margem ao livre arbítrio da Administração Pública, Mendes rebate que tal pensamento está equivocado, já que só seria possível falar em decisões arbitrárias por parte da Administração de modo a prejudicar os cidadãos com medidas extremas e desproporcionais ao ataque sofrido caso não houvesse lei a regular o abuso de autoridade - o que não é o caso, já que o ordenamento jurídico brasileiro disciplina a matéria na lei 4.898 de 9 de dezembro de 1965.

Assim sendo, a tese de Gilmar Mendes, acompanhada por Dias Toffoli e Ricardo Lewandowski, superou os argumentos trazidos pelo ministro Edson Fachin, de sorte que o Habeas Corpus 141.949 foi denegado pelo Supremo Tribunal Federal, e a decisão proferida pelo Superior Tribunal Militar se manteve.

\section{ALGUNS REFLEXOS DA DECISÃO DO STF NO JULGAMENTO DO HABEAS CORPUS 141.949 EM LITÍGIOS POSTERIORES}

O Habeas Corpus 141.949 julgado pelo Supremo Tribunal Federal em 2018 foi responsável por formular importante precedente ao entender que a tipificação do desacato na legislação penal brasileira não afronta o direito à liberdade de expressão da Convenção Americana sobre Direitos Humanos ou da Constituição Federal vigente. Assim sendo, a fundamentação do referido julgado foi utilizada como base em litígios posteriores sobre o tema.

É o caso do Agravo Regimental no Habeas Corpus 143.968, do Rio de Janeiro, sob relatoria do Ministro Ricardo Lewandowski, julgado pela Segunda Turma do Supremo Tribunal Federal em junho de 2018 que pugnou pela improcedência da

RC: 91174

Disponível em: https://www.nucleodoconhecimento.com.br/lei/ordenamento-juridico 
alegação de incompatibilidade do crime de desacato previsto na legislação penal militar com o disposto na Convenção Americana sobre Direitos Humanos. $\mathrm{Na}$ ocasião, o Ministro relator sustentou que:

Bem examinados os autos, verifico que a pretensão recursal não merece prosperar. Isso porque, além de o agravante repisar os argumentos aduzidos na inicial, de modo a não atacar os fundamentos da decisão agravada, a matéria em questão já foi decidida no âmbito da Segunda Turma, no julgamento do HC 141.949/DF, de relatoria do Ministro Gilmar Mendes, verbis:

'Habeas corpus. 2. Crime de desacato a militar (art. 299 do Código Penal Militar). 3. Controle de constitucionalidade (arts. 1우 $5^{\circ}$, incisos IV, V e IX, e 220 da Constituição Federal) e de convencionalidade (art. 13 da Convenção Americana de Direitos Humanos (Pacto de São José da Costa Rica). 4. Alegada ofensa à liberdade de expressão e do pensamento que se rejeita. 5. Criminalização do desacato que se mostra compatível com o Estado Democrático de Direito. 6. Ordem denegada' (HC 141.949/DF, Rel. Min. Gilmar Mendes).

Dessa forma, verifico que a tese sustentada pelo impetrante não encontra guarida nos recentes julgados do Supremo Tribunal de Justiça e do Supremo Tribunal Federal, o que demonstra, ainda, a exatidão do acórdão prolatado pela Corte castrense. (BRASIL, Supremo Tribunal Federal. Agravo Regimental. Agravo Regimental no Habeas Corpus no 143.968, 2018, p. 08.)

Na mesma esteira, encontra-se o Agravo Regimental no Recurso Extraordinário com Agravo 1.225.968 de São Paulo julgado pela Segunda Turma do Supremo Tribunal Federal em novembro de 2019, sob relatoria do Ministro Celso de Mello, a qual entendeu pela improcedência do agravo que pretendia afastar o crime de desacato cometido pelo agravante utilizando-se do argumento de que sua condenação confrontaria o preceito de liberdade de expressão disposto na Convenção Americana de Direitos Humanos e na Constituição Federal vigente. Em sua fundamentação, o Ministro relator dispôs que:

De qualquer maneira, no entanto, e mesmo que se pudesse superar tal óbice, ainda assim não se revelaria viável o apelo extremo a que se refere o presente agravo. É que a Segunda Turma desta Suprema Corte, ao julgar o HC 141.949/DF, Rel. Min. GILMAR MENDES, fixou entendimento que torna inacolhível a pretensão deduzida pela parte ora recorrente: "'Habeas corpus'. 2. Crime de desacato a militar (art. 299 do Código Penal Militar). 3. Controle de constitucionalidade (arts. 1우 $5^{\circ}$, incisos IV, V e IX, e 220 da Constituição Federal) e de convencionalidade (art. 13 da Convenção Americana de Direitos Humanos (Pacto de São José da Costa Rica). 4. Alegada ofensa à

RC: 91174

Disponível em: https://www.nucleodoconhecimento.com.br/lei/ordenamento-juridico 
liberdade de expressão e do pensamento que se rejeita. 5. Criminalização do desacato que se mostra compatível com o Estado Democrático de Direito. 6. Ordem denegada." Sendo assim, e em face das razões expostas, nego provimento ao presente agravo interno, mantendo, em consequência, por seus próprios fundamentos, a decisão recorrida, e indefiro o pedido de suspensão do processo. (BRASIL, Supremo Tribunal Federal. Agravo Regimental. Agravo Regimental no Recurso Extraordinário com Agravo $1.225 .968,2019$, p. 08.)

Ainda neste diapasão, tem-se a Arguição de Descumprimento de Preceito Fundamental 496, do Distrito Federal, julgada em junho de 2020, sob a relatoria do Ministro Roberto Barroso. O Tribunal Pleno julgou o pleito improcedente por maioria dos votos ao sustentar que o crime de desacato previsto na legislação penal foi recepcionado pela Constituição Federal de 1988, de modo que não há violação à liberdade de expressão. Na oportunidade, o Ministro relator arguiu que:

49. Também no campo penal é razoável que se prevejam tipos penais protetivos da atuação dos agentes públicos. É nesse contexto que se justifica a criminalização do desacato. Não se trata de conferir um tratamento privilegiado ao funcionário público. Trata-se, isso sim, de proteger a função pública exercida pelo funcionário, por meio da garantia, reforçada pela ameaça de pena, de que ele não será menosprezado ou humilhado enquanto se desincumbe dos deveres inerentes ao seu cargo ou função públicos.

50. Vê-se, portanto, que a diversidade de regime jurídico - inclusive penal existente entre agentes públicos e particulares é uma via de mão dupla: se existente justificativa razoável para tanto, as consequências previstas para as condutas típicas são diversas não somente quando os agentes públicos são autores dos delitos, mas, de igual modo, quando deles são vítimas.

51. Destaco, por fim, que ambas as turmas deste Tribunal já decidiram pela recepção da norma do art. 331 do Código Penal pela Constituição de 1988. Menciono, nesse sentido, os seguintes julgados: Habeas corpus. 2. Crime de desacato a militar (art. 299 do Código Penal Militar). 3. Controle de constitucionalidade (arts. 10; 5ำ, incisos IV, V e IX, e 220 da Constituição Federal) e de convencionalidade (art. 13 da Convenção Americana de Direitos Humanos (Pacto de São José da Costa Rica). 4. Alegada ofensa à liberdade de expressão e do pensamento que se rejeita. 5. Criminalização do desacato que se mostra compatível com o Estado Democrático de Direito. 6. Ordem denegada. (HC 141949, Rel. Min. Gilmar Mendes, Segunda Turma, j. 13.03.2018). (BRASIL, Supremo Tribunal Federal. Arguição de Descumprimento de Preceito Fundamental. Arguição de Descumprimento de Preceito Fundamental $n=496,2020$, p. 18.).

RC: 91174

Disponível em: https://www.nucleodoconhecimento.com.br/lei/ordenamento-juridico 
Diante do panorama apresentado, resta clara a contribuição do julgamento do Habeas Corpus 141.949 pelo Supremo na jurisprudência pátria em ações subsequentes. A citação do referido julgado nestes litígios cristaliza o entendimento de que a integridade do Poder Público não deve estar sujeita a ataques, verbais ou não, que o desmoralizem.

\section{CONSIDERAÇÕES FINAIS}

A recepção dos tratados de direitos humanos pelo ordenamento pátrio trouxe benefícios inéditos aos indivíduos. De acordo com Piovesan (2013), esse método de incorporação de documentos internacionais passou a permitir que normas sobre o assunto passassem a ser dotadas de um valor jurídico-normativo mais robusto. Assim, o reconhecimento desses direitos e garantias fundamentais e da dignidade da pessoa humana tornam-se ainda mais efetivos, de modo a formar uma espécie de "bloco" regulamentário multidisciplinar sob a ótica jurídica e sob a égide do princípio pro homine.

Quando do julgamento do Habeas Corpus 141.949, realizado pela Segunda Turma do STF em 2018, restaram-se verificadas duas correntes de entendimento: uma que interpreta o desacato como crime tipificado pelo ordenamento jurídico brasileiro e passível de punição, e a outra que entende a sua criminalização como um cerceamento aos direitos e garantias fundamentais dos cidadãos no que diz respeito à liberdade de expressão e de pensamento, defendendo que não haveria de existir sanções para tal, ainda que esses direitos e garantias devam ser exercidos dentro dos limites do bom senso coletivo, uma vez que o indivíduo detentor da autoridade, seja civil ou militar, representa do Estado brasileiro.

Com relação ao cerceamento do direito fundamental à liberdade de expressão em caso de desacato, tem-se a interpretação do célebre jurista Hungria (1959). Sob a sua ótica, o crime de desacato atenta contra a integridade da Administração Pública à qual os cidadãos brasileiros têm direito, prejudicando assim a eficiência do Poder Público. O referido autor defende que o funcionário público deve estar protegido de 
quaisquer ameaças ou violências durante o exercício de sua função como representante do Estado. Apesar da diversidade quanto ao alcance da norma, a seu ver, descriminalizar o desacato, deixando o funcionário público sem qualquer respaldo ou proteção para que possa exercer o que the foi incumbido pelo Estado, está fora de questão. Sustenta ele que o referido tipo penal é necessário para que se garanta a ordem jurídica e que tal prática se faz presente desde a Era Romana. A interpretação de Hungria (1959) explicita que a ofensa, ameaça ou violência a funcionários públicos no exercício de sua função pode tanto ser vista como uma forma agravada de injúria, quanto como crime sui generis.

Na mesma linha de raciocínio, encontra-se Capez (2005) ao argumentar que o artigo 331 do Código Penal Brasileiro, que versa sobre o desacato a funcionário público no exercício da função, tem o condão de resguardar a dignidade e prestígio que os cidadãos devem ter em relação aos que exercem a função pública. Corrobora também que o respeito é elemento essencial para que a execução dos atos funcionais da Administração Pública se dê com a máxima eficácia, já que o funcionário público é a personificação da vontade estatal. Para ele, o argumento de que o indivíduo que proferiu as ofensas estaria inebriado pela emoção não justifica a desconsideração de qualquer que seja o crime, visto que o desacato prejudica o andamento da máquina pública, bem como da atividade administrativa.

De acordo com o entendimento trazido por Piovesan (2013), faz-se mister compreender o Direito Constitucional Internacional como um grande fator influenciador das constituições das nações soberanas, principalmente dentro da ótica dos Direitos Humanos. Sendo assim, é fundamental a observância destes preceitos internacionais para que a proteção dos direitos da pessoa humana seja, de fato, efetiva. Conforme defendido por Loureiro (2004), é possível compreender uma automaticidade em relação à ratificação dos tratados de Direito Internacional dos Direitos Humanos pelo Brasil já que, ao incorporá-los ao direito pátrio, presume-se que tais normas passarão a fazer parte dos direitos e garantias reconhecidos aos cidadãos. 
Dessarte, ainda que haja controvérsias acerca do tema, a partir do momento em que a alta cúpula do Poder Judiciário, responsável pela aplicação do controle de constitucionalidade e do controle de convencionalidade, entende que o crime de desacato não desrespeita o direito à liberdade de expressão existente no sistema normativo pátrio e os tratados internacionais por ele recepcionados, constata-se uma maior segurança jurídica em caso de futuras demandas judiciais sobre a matéria.

\section{REFERÊNCIAS}

BRASIL. Constituição da República Federativa do Brasil: promulgada em 5 de outubro de 1988.

BRASIL. Decreto-Lei 2.848, de 07 de dezembro de 1940. Código Penal. Diário Oficial da União, Rio de Janeiro, 31 dez. 1940.

BRASIL. Decreto-Lei 1.001, de 21 de outubro de 1969. Código Penal Militar. Diário Oficial da União, Brasília, 21 out. 1969.

BRASIL. Decreto 678, de 06 de novembro de 1992. Convenção Americana sobre Direitos Humanos. Diário Oficial da União, Brasília, 09 nov. 1992.

BRASIL. Superior Tribunal Federal. Agravo Regimental. Agravo Regimental no Habeas Corpus no 143.968, da 2 ${ }^{\mathrm{a}}$ Turma. Direito penal e processual penal. Constituição Federal. Convenção Americana de Direitos Humanos. Crime de desacato a militar. Legitimidade. Liberdade de expressão. Relator Min. Ricardo Lewandowski, DJe, Brasília, 06 ago. 2018.

BRASIL. Superior Tribunal Federal. Agravo Regimental. Agravo Regimental no Recurso Extraordinário com Agravo 1.225.968, da 2a Turma. Direito penal e processual penal. Constituição Federal. Convenção Americana de Direitos Humanos. Crime de desacato a funcionário público. Legitimidade. Liberdade de expressão. Relator Min. Celso de Mello, DJe, Brasília, 16 dez. 2019. 
BRASIL. Superior Tribunal Federal. Arguição de Descumprimento de Preceito Fundamental. Arguição de Descumprimento de Preceito Fundamental no 496, do Plenário. Direito penal e processual penal. Constituição Federal. Convenção Americana de Direitos Humanos. Crime de desacato a funcionário público. Legitimidade. Liberdade de expressão. Relator Min. Roberto Barroso, DJe, Brasília, 24 set. 2020.

BRASIL. Superior Tribunal Federal. Recurso de Habeas Corpus. Habeas Corpus no 141.949, da 2ª Turma. Direito penal e processual penal. Constituição Federal. Convenção Americana de Direitos Humanos. Crime de desacato a militar. Legitimidade. Liberdade de expressão. Relator Min. Gilmar Mendes, DJe, Brasília, 13 mar. 2018.

CAPEZ, Fernando. Curso de direito penal: parte especial. 2. ed., São Paulo: Saraiva, 2005. v.3

GALINDO, George Rodrigo Bandeira. Tratados internacionais de direitos humanos e a Constituição brasileira. Belo Horizonte: Del Rey, 2002.

HUNGRIA, Nelson. Comentários ao Código Penal: Decreto-lei n. 2.848, de 7 de dezembro de 1940, Arts. 250 < 361. Rio de Janeiro: Revista Forense, 1959.

LOUREIRO, Sílvia Maria da Silveira. Tratados internacionais sobre direitos humanos na Constituição. Belo Horizonte: Del Rey, 2004.

MAZZUOLI, Valerio de Oliveira. Teoria geral do controle de convencionalidade no direito brasileiro. Revista dos Tribunais, v. 889, p. 105- 48 , nov. 2009. Disponível em: <https://www.revistadostribunais.com.br/maf/app/search/run>. Acesso em: 17 jun. 2021.

OEA. Convenção Americana sobre Direitos Humanos. Disponível em:<https://www.cidh.oas.org/basicos/portugues/c.convencao_americana.htm>. Acesso em: 06 jul. 2021. 
PIOVESAN, Flávia. Direitos humanos e o direito constitucional internacional. 14. ed., rev. e atual. São Paulo: Saraiva, 2013.

REZEK, José Francisco. Direito internacional público : curso elementar. 13. ed., rev., aum. e atual. São Paulo: Saraiva, 2011.

Enviado: Julho, 2021.

Aprovado: Julho, 2021. 